\title{
Study of the Impact of Knowledge Deployment and Appetite for Change on Work
}

\author{
Maryam Joharishirazi ${ }^{1 *}$ and Delaram Chehelmard ${ }^{2}$ \\ ${ }^{1} \mathrm{PhD}$ Scholar, Faculty of Management and HRM, Bhagwant University, Ajmer, India \\ ${ }^{2}$ MBA, School of Management Studies, Jawaharlal Nehru Technological University Hyderabad, India
}

\begin{abstract}
The necessary precursor to high levels of student achievement is deep engagement in learning, and the teacher's own engagement is the key to achieving that. Work engagement may be defined as a positive, fulfilling, work-related psychological state characterized by the dimensions of vigor, dedication, and absorption. This research has been carried out to analyze the impact of Appetite for Change and Knowledge Deployment (two of the seven components of Organizational Intelligence) on work engagement among a sample of 141 secondary school teachers in Hyderabad, Andhra Pradesh, India in March and April 2013. The measurement instruments used in this study were the Utrecht Work Engagement Scale and Albrecht Organizational Intelligence questionnaire (2003). The method of this research is descriptive correlation. The outcome of the research showed that there is a positive and significant relationship between the two components: Appetite for Change and Knowledge Deployment, and teachers' work engagement. In addition, the reliability of the UWES-9 was investigated by using Cronbach's alpha coefficient which was high (alpha $=.86$ overall) and the results showed that teachers' level of work engagement is generally high (overall $M=5.40$ on the 7 -point scale).
\end{abstract}

Keywords: Appetite for change; Knowledge deployment; Organizational intelligence; Positive organizational behavior; Work engagement

\section{Introduction}

Since the emergence of positive psychology, it has become increasingly acknowledged that negative psychological states constitute only one part of the spectrum of the experienced psychological states in the workplace, and that positive behaviors, cognitions, and emotions are also prevalent and in need of study. Luthans [1] defined Positive Organizational Behavior as 'the study and application of positively oriented human resource strengths and psychological capacities that can be measured, developed, and effectively managed for performance improvement in today's workplace.'

One of the constructs of positive organizational behavior is work engagement; a psychological state considered the opposite pole of burnout [2]. Work engagement is defined as "a positive, fulfilling, work-related state of mind characterized by vigor, dedication and absorption. Vigor is characterized by high levels of energy and mental resilience while working, the willingness to invest effort in ones work and persistence in the face of difficulty. Dedication is ones" sense of significance, enthusiasm, inspiration, pride and challenge. Absorption refers to the state in which one is highly concentrated and happily engrossed in works so that s/he feels time passes quickly and it is difficult to detach from work. Engaged teachers, therefore, feel strong and vigorous at work, enthusiastic and optimistic about the work they do and are very often immersed in that work.

The concept of engagement is also applicable to teaching profession. Since the necessary precursor to high levels of student achievement is deep engagement in learning, and the teacher's own engagement is the key to achieving that, work engagement among teachers have also received important attention nowadays.

A number of research and literature on work engagement has offered somewhat different definitions of what work engagement is. Kirkpatrick, for example, uses the word job engagement to refer to employee's interest in, enthusiasm for and investment in his or her job. She further says that empirical studies have revealed that job engagement is associated with various positive behaviors and outcome for both employees and the organization.

According to Kahn, Work engagement is a construct that captures the variation across individuals and the amount of energy and dedication they contribute to their job. It is defined as the simultaneous employment and expression of a person's preferred self during tasks that promote connections to work and to others, personal presence and active, full performances.

May, Gilson and Harter also conceptualized work engagement and describe the three dimensions as components: a physical component, an emotional component, and a cognitive component. The physical component is described as energy used to perform the job; the emotional component is described as putting one's heart into one's job; and the cognitive component is described as being absorbed in a job so much that everything else is forgotten.

Research has suggested that the level of work engagement in general is affected by personal characteristics, the work place and the characteristics of the work, including job status and job demands [3].

Balain and Sparrow [4] agree that engagement levels co-vary with biographical factors such as how old a person is and their gender, as well as more work-related factors such as how new they are to the organization, their working hours, their pay and where they sit in the organization.

*Corresponding author: Maryam Joharishirazi, PhD Scholar, Faculty of Management and HRM, Bhagwant University, Ajmer, India, Tel: 00971526274830; E-mail:1204457@gmail.com

Received October 15, 2014; Accepted December 24, 2014; Published January 02, 2015

Citation: Joharishirazi M, Chehelmard D (2015) Study of the Impact of Knowledge Deployment and Appetite for Change on Work. J Account Mark 4: 120. doi: 10.4172/2168-9601.1000120

Copyright: ( 2015 Joharishirazi M, et al. This is an open-access article distributed under the terms of the Creative Commons Attribution License, which permits unrestricted use, distribution, and reproduction in any medium, provided the original author and source are credited. 
Blessing white's survey of over 7,500 individuals and interviews with senior human resource and line managers found that at least a quarter of Generation Y employees globally are disengaged with the exception of India, where all generations have higher engagement levels than other regions. They suggest that the older the employee, the more engaged they are [5].

Roles and seniority make a big difference to the level of engagement. Towers Perrin [6] survey data suggests that, generally, the more senior an individual's role within an organization, the greater the chance of being engaged. This is akin to studies of Generation $Y$ which suggested that increased engagement is expected to be an outcome of power and position.

According to Hakanen, Bakker and Schaufeli $[7,8]$, the Journal of School Psychology, there are two parallel processes involved in workrelated well-being among teachers, namely an energetically process (i.e., job demands $\rightarrow$ burnout $\rightarrow$ ill health) and a motivational process (i.e., job resources $\rightarrow$ engagement $\rightarrow$ organizational commitment). Job resources refer to those physical, psychological, social, or organizational aspects of the job that may

(1) Reduce job demands and the associated physiological and psychological costs

(2) are functional in achieving work goals and

(3) Stimulate personal growth, learning, and development.

These researchers included five job resources that have been identified either as major motivators that increase commitment or engagement, or that-when lacking-act as factors that increase burnout:

(1) Job control

(2) Access to information

(3) Supervisory support [9]

(4) Innovative school climate

(5) Social climate

Schaufeli, Salanova, Gonzalez-Roma, and Bakker identified work engagement as a positive, fulfilling, work-related state of mind that is characterized by vigor, dedication, and absorption. The present study is based on this approach to work engagement.

Organizational intelligence is an aspect of organizational behavior and plays an important role in organizations. One of the greatest management challenges in the recent decades is the creation of intelligent institutes, because organizations may like human being fail to use their intelligence [10]. Albrecht [11] believes that the answer to this question may depend on the intelligence of an organization, i.e. an organization should learn to investigate based on the intellectual potential of the personnel employed by it. There may be so many intelligent and motivated individuals of an organization, who may change to inefficient and motiveless people due to working for many years in an organization in vain.

Organizational intelligence studies help to identify the organizational situations in terms of intelligence i.e. the ability of adapting with environment, perspective, acquiring knowledge, organizational performance and structure, mood, communication and information technology, as well as organizational memory in order to focus on the abilities and plan for removing the weaknesses, and improve efficiency and effectiveness of the organization [12].
McMaster regards it as organization-level thinking, the capacity to behave flexible and creative. Organizational intelligence may also be viewed as all the abilities of organizations to exhibit intelligent behavior [13].

Halal has defined Organizational Intelligence as the capacity of an organization to create knowledge and use it to strategically adapt to its environment. A higher OIQ doesn't necessarily improve performance; any more than a high IQ ensures success in life. Rather, it's the fit between OIQ and environment that determines performance.

According to Arstin main components of intelligent organizations include ability to make change, ability to fast action and reaction, ability to use imaginations, efficient management and using human resources, efficient factors, technology, knowledge and ability of organizational learning. To prevent dullness of some people, Albrecht uses organizational intelligence. Based on this viewpoint organizational intelligence consists of organizational capacity to apply all its brain powers and the focus of that brain powers on its commission (Graph 1). Karl Albrecht has defined seven dimensions for this concept which are as follows:

1. Strategic Vision: It refers to the capacity of providing goals.

2. Shared Fate: It means having a common goal, unanimity and coordination with the goals.

3. Appetite for Change: Flexibility capacity and more compatibility with environmental changes.

4. Heart: It shows the tendency to the activity beyond the standard.

5. Alignment and Congruence: Elimination of contradictions and promotion of individual energy appropriate for achieving common goals.

6. Knowledge Deployment: The ability of creation, transition, organizing, participating and applying knowledge.

7. Performance Pressure: Forming the culture in which each new member that join the organization feels cooperation binding toward job.

Stokyko was expressed that there is significant relationship between organizational memory (intelligence of organizational) and organizational culture. As the relationship between organizational culture and organizational intelligence is described, advice is offered to managers about what to do to create a culture that supports learning. Developing a culture that supports learning involves creating a "safe space" wherein people can speak candidly, reflect on what they do, and act authentically. This can lead to higher work engagement.

The purpose of this research is whether there is any relationship

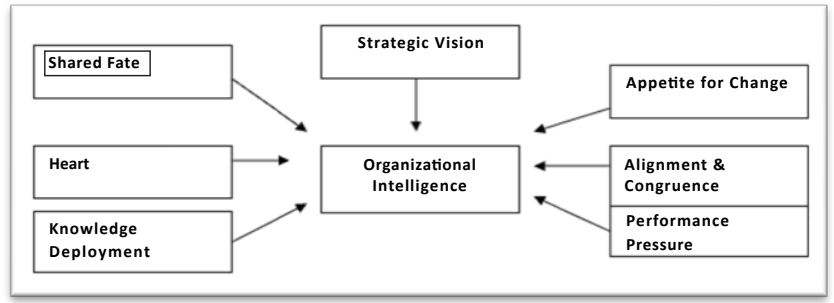

Graph 1: Albrecht Organizational Intelligence Model-Resource: Albrecht 2003. 
between work engagement and two of the seven dimensions of Albrecht Organizational Intelligence model: Appetite for Change, Knowledge Deployment:

\section{Knowledge deployment}

More and more these days, enterprises succeed or fail based on the effective use of knowledge, information, and data. Almost every organization these days depends heavily on the acquired knowledge, know-how, judgment, wisdom, and shared sense of competency possessed by its people, as well as the wealth of operational information that flows through its structure every minute. The capacity to create, transform, organize, share, and apply knowledge is becoming an ever more critical aspect of competing in complex environments Going well beyond the current IT formulas for "knowledge management," knowledge deployment deals with the capacity of the culture to make use of its valuable intellectual and informational resources. In this respect, knowledge deployment probably deserves to be conceived of as an anthropological proposition rather than a technological or structural one. OI must include the free flow of knowledge throughout the culture, and the careful balance between the conservation of sensitive information and the availability of information at key points of need. It must also include support and encouragement for new ideas, new inventions, and an open-minded questioning of the status quo.

Today, knowledge is in the heart of global economy and knowledge management $(\mathrm{KM})$ is a vital factor in achieving organizational success. Knowledge management is accounted as main Component of process and structure of any training organization [14]. Schools are extendedly dependent on mental and human capitals for knowledge distribution.

\section{Appetite for change}

Some organizational cultures, usually led by their executive teams, have become so firmly set in their ways of operating, thinking, and reacting to the environment that change represents a form of psychological discomfort or even distress. In others, change represents challenge, opportunity for new and exciting experiences, and a chance to tackle something new. People in these environments see the need to reinvent the business model as a welcome and stimulating challenge, and a chance to learn new ways of succeeding. The appetite for change needs to be big enough to accommodate the kinds of changes called for in the strategic vision.

According to the Job Demands-Resources (JD-R) Model [15], innovative school climate, and access to information, are among the five job resources that have been identified as major motivators that increase commitment or engagement. Consequently the two components of Albrecht Organizational Intelligence model: Appetite for Change and Knowledge Deployment has been hypothesized in this study to have a significant positive impact on work engagement among secondary school teachers.

Since educational institutions play a crucial role in social systems, implementation of such applied research can lead to promotion of work engagement among teachers and prepare a suitable situation at school to improve their work engagement which eventually can lead to effective education and more productive human resources.

\section{Research objectives}

(i) To study the level of Work engagement among secondary school teachers,

(ii) To study the level of Knowledge Deployment, Appetite for Change levels based on the perceptions of the secondary school teachers in Hyderabad,

(iii) To study the impact of Knowledge Deployment, and Appetite for Change on teachers' work engagement

\section{Hypothesis}

(i) There is significant relationship between Appetite for Change and teachers' work engagement

(ii) There is significant relationship between Knowledge Deployment and teachers' work engagement

\section{Knowledge management strategy vs knowledge strategy}

Knowledge strategy has been identified as one of three meanings used for KM strategy, with a focus on knowledge-based competitive advantage vs either an approach to KM or the implementation of KM. $\mathrm{KM}$ refers to the portfolio of procedures and techniques used to get the most from a firm's knowledge assets. While KM strategy deals with structural and technical management issues, knowledge strategy deals with business outcomes and support for competitive advantage.

For example, Zack's knowledge strategies of exploration and exploitation focus on the application of knowledge within the firm, while Hansen et al.'s KM strategies of codification and personalization focus on the structuring of knowledge within the firm. Earl's KM strategy taxonomy supports this differentiation, as the focus and aim of each of the seven schools revolves around the management of knowledge rather than its application for competitive purposes. In contrast, Casselman \& Samson identify seven components of knowledge strategy that relate to generating competitive advantage: internal organization, measurement and reward, boundaries, knowledge advantage, protection, disaggregation, and investment intensity. While the importance of KM strategy is acknowledged, this paper focuses exclusively on knowledge strategy.

\section{Knowledge strategy dimensions}

To compare the two typologies, each knowledge strategy type is described in a synthesis of the underlying dimensions of both knowledge strategy typologies. Specifically, knowledge source, radicalness of learning, speed of learning, and scope of knowledge are drawn from Bierly and Chakrabarti and knowledge creation and knowledge transfer are taken from von Krogh et al.. By examining all eight types through each dimension used to create both typologies, a more detailed understanding of their relationships can be established. In addition, as knowledge strategy guides resource allocation, these dimensions are representative of organizational decisions and tendencies regarding the application of knowledge assets.

\section{Knowledge source}

Primary knowledge source refers to where the organization gets its knowledge from Zack. Internal learning occurs when new knowledge is generated and distributed by members within the organization; external learning occurs when organizational members bring in knowledge from outside the firm. Internally generated knowledge tends to be unique, specific, and tacitly held, and hence, difficult to imitate; externally generated knowledge tends to be more abstract, packaged, and widely available, and hence, more easily imitated. Knowledge source is divided into internal and external aspects to address the fact that some firms balance internal and external learning. 


\section{Knowledge process}

Organizational knowledge creation is the process of making available and amplifying knowledge created in individuals as well as crystallizing and connecting it with an organization's knowledge system'. Primary knowledge process refers to the core knowledge processes of creation and transfer. The specific focus of the organization may be on the creation of new knowledge or the application of existing knowledge and the degree of balance between the two. Knowledge process is divided into creation, and transfer, reflecting the tension between the two aspects and the firm's ability to potentially master both.

\section{Knowledge focus}

How organization uses knowledge defines its strategy in terms of its knowledge focus. One extreme is exploration, where the firm focuses on creating or acquiring new knowledge in order to stay competitive. The other extreme is exploitation, where the organization uses slack knowledge resources to further develop a competitive position. There is a natural tension in an organization between assimilating new knowledge through exploration and using existing knowledge through exploitation. However, these two aspects are not mutually exclusive, as certain knowledge areas may be exploited while others are explored.

\section{Radicalness of learning}

Learning can be defined as 'a relatively permanent change in knowledge... produced by experience'. Radical learning challenges the basic assumptions of the organization, whereas incremental learning gradually expands the firm's knowledge base. In general, the concept of absorptive capacity suggests that to understand, evaluate, and use outside knowledge, the firm must have a level of prior related knowledge. This may limit the ultimate degree of radicalness of the ideas an organization can assimilate, as an organization must first recognize the potential value of new knowledge before it can be considered to be 'learned'.

\section{Speed of learning}

Speed of learning in competitive markets is important because the most competitive knowledge position involves knowledge that is codified and most easily-but yet to be-diffused. Faster learning extends the gap between a firm's ability to replicate its knowledge and its competitors' ability to imitate it. Slower rates of learning, however, have the benefit of letting a firm evaluate knowledge positions in the market, allow complementary streams of knowledge to develop together, and integrate knowledge more effectively once environmental uncertainty has been reduced.

\section{Scope of knowledge}

Breadth reflects the extent to which a firm's knowledge is specialized or generalized, whereas depth refers to the degree to which a firm develops a specific domain of knowledge. A narrow focus adopted to develop a deep knowledge base may lead to the development of core competencies; a wide focus adopted to develop a broad knowledge base may lead to a combination of related technologies and knowledge. A firm's absorptive capacity is based upon its scope of prior knowledge in the domain. Maintaining too narrow and deep a knowledge base may prevent the recognition of new knowledge outside of this specialized area; however, maintaining too broad and shallow a knowledge base may leave the firm without the requisite understanding to assimilate and synthesize that same knowledge. As the scope of knowledge can be both broad and deep, these dimensions have breadth and depth aspects that are not mutually exclusive.

\section{Methods}

\section{Participants and Procedure}

A questionnaire was delivered to 15 high schools (207 teachers) in Hyderabad in March and April 2013. The respondents were teachers from grade 6 to 10 i.e. secondary school teachers. Data collection was carried out with the prior permission of the school principal or manager. Statements were presented in English. 141 teachers completed and returned the questionnaire anonymously in an envelope. The response rate was $68 \%$. Most participants were female (89.4\%): $12.8 \%$ of the teachers were $18-24$ years old, $51.8 \%$ were $25-34$ years, $26.2 \%$ were $35-44$ years, $9.2 \%$ were $45-55$ years, and no respondent was older than 55 years.

\section{Measurement Instrument}

Work engagement was measured by means of the Utrecht Work Engagement Scale (UWES-9), which includes three three-item scales: Vigor (VI), Dedication (DE), and Absorption (AB) [16]. Engaged workers are characterized by high levels of vigor and dedication, and they are immersed in their jobs. Responses to items are given on a frequency scale varying from 0 (never) to 6 (always). The UWES has been validated in several countries, including China, Finland, Greece, South Africa [17], Spain, and The Netherlands [18]. The UWES-9 has been shown to have good construct validity, suggesting high correlation to the theorized construct of engagement.

To measure the components of Appetite for Change, and Knowledge Deployment, the respective subscales in "Organizational Intelligence Questionnaire" were used. This is a five point Likert-scale with response range varying from 1 for "strongly disagree" to 5 for "strongly agree".

Nunnally and Bernstein [19] suggest 0.70 as an acceptable reliability coefficient. Table 1, shows the internal consistencies (Cronbach's $\alpha$ ) of the scales. The internal consistencies are quite good for the UWES9 (alpha $=.860)$ and VI, DE, and AB subscales $(.721, .829$, and .730 , respectively). The internal consistencies (Cronbach's $\alpha$ ) of the scales "Appetite for Change" and "Knowledge Deployment" are also quite good.

\section{Analysis}

The analyses were run by means of analytical tools available in SPSS. Table 2 presents some of the demographic characteristics of the participants.

Among the sample group of 141 teachers, just 15 respondents were males and 126 were females. In addition, a majority $51.8 \%$ of the respondents was from the age group 25 to 34 years, and just $9.2 \%$ were from 45 to 54 years and no respondent was above 54 years of age. In terms of work experience of the teachers in this study, $35.5 \%$ of the respondents had 6-15 years of work experience while most of the

\begin{tabular}{|l|c|}
\hline $\mathbf{( N = 1 4 1 )}$ & Cronbach's Alpha \\
\hline UWES-9 & .860 \\
\hline Vigor (VI) & .721 \\
\hline Dedication (DE) & .829 \\
\hline Absorption(AB) & .730 \\
\hline Appetite for change & .771 \\
\hline Knowledge Deployment & .840 \\
\hline
\end{tabular}

Table 1: Cronbach's a of the UWES-scales. 


\begin{tabular}{|l|l|c|}
\hline Item & Category & Percentage \\
\hline Gender & Female & 89.4 \\
\hline & Male & 10.6 \\
\hline Age & 18-24 years old & 12.8 \\
\hline & 25-34 years old & 51.8 \\
\hline & 35-44 years old & 26.2 \\
\hline & 45-54 years old & 9.2 \\
\hline Experience & 55+years old & 0 \\
\hline & Less than 2 years & 20.6 \\
\hline & 3-5 years & 30.5 \\
\hline & 6-15 years & 35.5 \\
\hline Education & More than 15 years & 13.5 \\
\hline & 3 Year Degree & 32.6 \\
\hline & 4 Year Degree or Honour & 19.9 \\
\hline & Master's Degree & 47.5 \\
\hline & Doctoral Degree & 0 \\
\hline
\end{tabular}

Table 2: Characteristics of the participants.

\begin{tabular}{|l|c|c|}
\hline Dimensions & $\boldsymbol{M}(\mathbf{S D})$ & Teachers' perception \\
\hline Processes Always Evolving & 3.82 & Agree \\
\hline Encouraged to Improve Job and amp; innovate & 4.09 & Agree \\
\hline Minimum Bureaucracy & 3.69 & Agree \\
\hline principal/managers Admit Mistakes & 3.68 & Agree \\
\hline Atmosphere for Change & 4.11 & Agree \\
\hline Appetite for change & 3.87 & Agree \\
\hline Culture of Sharing Know & 4.01 & Agree \\
\hline Mgrs Respect Knowledge & 3.96 & Agree \\
\hline school allow sharing the learnings & 3.92 & Agree \\
\hline Operating Info Flows & 3.45 & Neutral \\
\hline principal/teachers Study Latest Ideas & 3.69 & Agree \\
\hline Emp Learning and Development & 3.68 & Agree \\
\hline Knowledge Deployment & 3.78 & Agree \\
\hline
\end{tabular}

Table 3: Descriptive statistics of the study variables.

teachers (51.1) had less than 5 years of work experience, and (13.5\%) had more than 15 years of experience. Finally, approximately half of the teachers (47.5\%) had Master's degree and there was no teacher with Doctoral Degree.

To realize the average perception of teachers about each of the aspects of the Appetite for change and Knowledge Deployment, the mean of each item of the construct was calculated. As can be seen in the Table 3 the average perception of sample group of teachers about the existence of all items except the item "Operating Info Flows", is Agree. In other words in average teachers agree that they have experienced each of the items at the school they are working in.

As can be seen from the Table 3, the factor "Appetite for change" has been agreed on by the teachers slightly higher than the factor "Knowledge Deployment".

Additional Descriptive statistics of the UWES-9 subscales suggests that the work engagement among the secondary school teachers under the study is generally high (average mean $=5.40$ on the 7-point Likerttype scale varying from 0 to 6 ). The average mean scores of the three subscales were $M=5.14$ for vigor, $M=5.65$ for dedication, and $M=5.41$ for absorption). Out of the three dimensions of engagement, dedication is found to be highest, followed by absorption and vigor. Thus the engagement of the teachers is determined more by the dedication.

This study uses Pearson's correlation analysis to determine the relationship between engagement level and Appetite for change and Knowledge Deployment. Table 4 Shows that significant and positive correlation exists between Appetite for Change and Engagement $(\mathrm{r}=.438, \mathrm{p}<.01)$. Therefore it supports the hypothesis" There is significant relationship between the level of Appetite for Change and work engagement among teachers". Also, the results show that significant and positive correlation exists between knowledge Deployment and Engagement $(\mathrm{r}=.359, \mathrm{p}<.01)$.

Further correlation analysis was conducted to analyze the relationship between Appetite for Change, and Knowledge Deployment, and three dimensions of work engagement. The results reveal that both Appetite for Change and Knowledge Deployment are related positively and significantly at the 0.01 level to all the three dimensions of engagement i.e Vigor, Dedication and Absorption. The correlation coefficient for Appetite for Change and Knowledge Deployment was found to be highest with vigor ( $\mathrm{r}=.474, .392$ respectively) followed by dedication $(\mathrm{r}=.348, .272)$ and then with absorption $(\mathrm{r}=.254, .218)$.

\section{Findings and Conclusion}

With data obtained from a sample of secondary school teachers in Hyderabad, it is found that the UWES-9 shows a good internal consistency reliability (alpha $=.86$ ), well above the suggested threshold of .70. The internal consistency of the three engagement scales is also acceptable (alphas $=.721, .829, .730$ respectively, for vigor, dedication, and absorption subscales). The internal consistencies (Cronbach's $\alpha$ ) of the scales "Appetite for Change" and "Knowledge Deployment" are also quite good. (alphas $=.771, .840$ respectively).

The results of the study reveal good level of work engagement $(M=5.40)$ among the sample group. Out of the three dimensions of work engagement Dedication $(M=5.65)$ was found to be most important determinant of engagement level followed by absorption $(M=5.41)$ and vigor $(M=5.14)$. These findings are consistent with the findings of Mauno et al., where health care workers experienced more dedication than vigor and absorption. Also, Pitt-Catsouphes et al. [20] reported that work engagement was high (5.5 overall) among respondents from worksites in India. As for the two components of organizational intelligence, the results show that according to teachers perception there is high level of Appetite for Change $(M=3.87)$, and Knowledge deployment $(M=3.78)$ in the sample group.

Results indicated that there is positive and significant relation between work engagement, and Appetite for Change $(\mathrm{r}=.438)$ and Knowledge deployment $(\mathrm{r}=.359)$. The research showed that is a positive and meaningful relation between these two components of organizational intelligence and the three dimensions of work engagement i. e Vigor, Dedication and Absorption.

\begin{tabular}{|c|c|c|c|c|}
\hline & & $\begin{array}{l}\text { Appetite for } \\
\text { change }\end{array}$ & $\begin{array}{l}\text { Knowledge } \\
\text { Deployment }\end{array}$ & Engagement \\
\hline \multirow[t]{3}{*}{ Appetite for change } & $\begin{array}{l}\text { Pearson } \\
\text { Correlation }\end{array}$ & 1 & $.755^{* *}$ & $.438^{* *}$ \\
\hline & Sig. (2-tailed) & & .000 & .000 \\
\hline & $N$ & 141 & 141 & 141 \\
\hline \multirow[t]{3}{*}{$\begin{array}{l}\text { Knowledge } \\
\text { Deployment }\end{array}$} & $\begin{array}{l}\text { Pearson } \\
\text { Correlation }\end{array}$ & $.755^{\star *}$ & 1 & $.359^{* *}$ \\
\hline & Sig. (2-tailed) & .000 & & .000 \\
\hline & $N$ & 141 & 141 & 141 \\
\hline \multirow[t]{3}{*}{ Engagement } & $\begin{array}{l}\text { Pearson } \\
\text { Correlation }\end{array}$ & $.438^{\star *}$ & $.359^{\star *}$ & 1 \\
\hline & Sig. (2-tailed) & .000 & .000 & \\
\hline & $N$ & 141 & 141 & 141 \\
\hline
\end{tabular}

Table 4: Correlation between the study variables. 
Citation: Joharishirazi M, Chehelmard D (2015) Study of the Impact of Knowledge Deployment and Appetite for Change on Work. J Account Mark 4: 120. doi: 10.4172/2168-9601.1000120

Page 6 of 6

Finally, since the study has been performed with a small sample size, further studies can be conducted using a larger sample. This study only used the views of teachers, considering school as an organization with different stakeholders such as students and parents; it is also recommended that further researches be carried out using the views of students, parents and other people who are interfering in the education system as well. It is also recommended to study other components of Organizational Intelligence in schools and examine their relationship with students' engagement and achievement.

\section{References}

1. Luthans $F(2002)$ The need for and meaning of positive organizational behavior J Organiz. Behav 23: 695-706.

2. Schaufeli WB, Salanova M, Gonza'lez-Roma V, Bakker AB (2002) The measurement of engagement and burnout: $A$ two sample confirmatory factor analytic approach. The Journal of Happiness Studies 3: 71-92.

3. Mauno S, Kinnunen U, Ruokolainen M (2007) Job demands and resources as antecedents of work engagement: a longitudinal study. J Vocat. Behav 70: 149-71.

4. Balain S, Sparrow P (2009) Engaged to Perform: A new perspective on employee engagement. Centre for Performance-LED HR, Lancaster University Management School.

5. Blessing White (2008) The State of Employee Engagement.

6. Towers Perrin (2003) Working Today: Understanding What Drives Employee Engagement, Towers Perrin, HR Services.

7. Hakanen JJ, Bakker AB, Schaufeli WB (2006) Burnout and work engagement among teachers. Journal of School Psychology 43: 495-513.

8. Demerouti E, Bakker AB, Nachreiner F, Schaufeli WB (2001) The Job Demands - Resources Model of burnout. Journal of Applied Psychology 86: 499-512.
9. Maslach C, Jackson SE, Leiter MP, Schaufeli WB, Schwab RL (1996) Maslach burnout inventory manual. Palo Alto7 Consulting Psychologists Press.

10. Halal W (2006) Organizational intelligence: What is it?

11. Albrecht K (2008) The Power of Minds at Work: Organizational Intelligence in Action. Karl Albrecht International, New York.

12. Cronquist $B$ (2004) Organizational intelligences; a dynamic knowledge creating activity embedded in organizational routines.

13. Richard V (2000) On Intelligence, component-Based Business Background Material.

14. Adhikari DR (2010) Knowledge Management in academic institutions. International Journal of Educational Management 24: 94-104.

15. Bakker AB, Demerouti Boer ED, Schaufeli WB (2003) Job demands and job resources as predictors of absence duration and frequency. Journal of Vocational Behavior 62: 341-356.

16. Schaufeli WB, Bakker AB (2004) Job demands, job resources, and their relationship with burnout and engagement. Journal of Organizational Behavior 25: 293-315.

17. Rothmann S, Storm K (2003) Work engagement in the South African Police Service. $11^{\text {th }}$ European Congress of Work and Organizational Psychology, Lisbon.

18. Schaufeli WB, Bakker AB (2003) UWES-utrecht work engagement scale: Preliminary manual. Department of Psychology, Utrecht University, Utrecht.

19. Nunnally JC, Bernstein IH (1994) Psychometric theory. McGraw-Hill, New York.

20. Sarkisian N, Catsouphes MP, Bhate R, Carapinha R, Pitt-Catsouphes, et al. (2011) Effects of Country and Age on Work Engagement, Job Satisfaction and Organizational Commitment among Employees in India. The Sloan Center on Aging and Work-Boston college. 